\title{
NERDS: THE PHENOMENON OF INTERTEXTUAL GARMENT BETWEEN WORSHIP AND DISTINCTION
}

\author{
Emiliano Chirchiano \\ Dr., Università degli studi di Napoli Federico II, ITALY, emiliano.chirchiano@unina.it
}

\begin{abstract}
Printed T-shirts are the characteristic garment, risen to the role of distinctive "uniform", used by one of the most representative socio-cultural phenomenon of the latest years: nerds. Rather than the style of the garment, more than its aesthetic dimension, I focus on T-shirt explicit semiotic content.

This paper aims to show how nerds could be considered as a universal cultural field based on consumption practices. How a label once considered a stigma became something to be proud of. How the choice of clothing becomes a complex tool for identity construction and community making.
\end{abstract}

Keywords: Mass Culture, Communication, Community, Cinema, Comics, Television, Fandom.

\section{WHO ARE THESE NERDS?}

For more than forty years the press announces, with cyclical regularity, "The revenge of the Nerds" or, with particular emphasis, their triumph. Complex labels, such as nerds or geeks, are not easy to define as they represent a complex network of social relations. Who are these nerds? How can we fit them in a sociologically relevant perspective? Existing studies generally focus on how the nerds are - directly and indirectly - represented, analysing practices of individual communities, ignoring, in my view, the full extent of the field. I suggest that what people conventionally call "nerd" or "geek" can be considered as a specific form of cultural practice lying in the sphere of consumption. Through these practices they create traditions and communities with a sense of identity.

Understanding the nature of these communities and their practices of signification helps us to understand the possibilities (and limitations) of recreating, from our daily experience, the sense of the original Gemeinschaft (Tonnies, 1897). Although the term was coined recently, nerds seem to have always been part of our imaginary. As Lori Kendall (2011: 517) wrote: "The image of the nerd persists in our culture because of the richness of references, and the plethora of narratives to which it connects. Embodied in the nerd are stories about economics, technology, gender, and race." The nerd is not defined just by the contrast between "practical" and "contemplative" man but also by specific stereotypes. They are often associated with particular interests and activities, such as collecting comic books, role-playing games, some literary genres (especially science fiction and fantasy), science and technology. These interests are pursued in a fanatic way, to the detriment of a "full" and "healthy" life. Many versions of this stereotype include specific physical characteristics (pallor, myopia, extreme thinness or obesity) and social behaviours (uneasiness in interpersonal relationships, difficulty to interact with the opposite sex) (Nugent, 2008). Overcoming these cruel caricature, it remains difficult to define what actually makes a nerd.

This - incomplete - list of traits suggests that the term "nerd" is a fairly large container of characteristics, sometimes poorly correlated; secondly, it suggests substantially negative connotation associated with the 
term. They are being referred to as, at best, as "mad scientists" or "geniuses", or more often as "losers" or even worse "sick", people suffering from some mental illness that would make them socially unsuitable or detestable. Terms like nerd and geek, though they may sound natural in our everyday social taxonomies, are mere labels. Sometimes applied to people (or fictional characters), sometimes claimed by them, but like all labels, subject to change over time.

To understand who really are those nerds, we can look at the movies or television programs, especially the popular ones, like a privileged viewpoint on the society and its mutations because, like Sergio Brancato (2010) states "The medium film is structurally one of those hot spots where you cannot escape the significance of what is happening here and now. (...) For the sociology all movies can - or rather must become objects of study".

Let's start from the movie "Revenge of the Nerds" (1988), historically known for introducing the classical image of the nerd. The nerd of "Revenge" seems, more than anything else, a simplistic parody. Perhaps its only merit is that it has captured the collective imagination the nerd: clumsy, wearing thick-rimmed glasses and short-sleeved shirts with front pocket full of pens. Nerd and geek representation has changed substantially in the last twenty-five years. In the late 1990s, thanks to the transformation of the economy made by the impact of information technology on daily life, academics and journalists started to positively transform the meaning of the term "nerd"; These are the years when the figure of Bill Gates becomes the paradigm of success: Clumsy, bespectacled and shy but at the same time the richest man in the world. Movies like "Pirates of silicon valley" (1998) or "Triumph of the nerds" (1996) show us this radical change of paradigm. The rise of the nerds as pop culture trend-setters in the 2000s helps us to even better understand the turnaround regarding their popularity. The perception of this success could be easily measured by looking at how the current mainstream tastes are dominated by genres once exclusively enjoyed by nerds. Whatever the unit of measurement is - commercial success, critical acclaim, and the cachet of celebrity - we can observe that cultural products whose nerds and geeks have traditionally been the main audience, today take a prominent place in popular culture.

The neo-classical nerd characters from the TV series "The Big Bang Theory" represents a clear reflection of this phenomenon. The protagonists, nerd and proud, have an updated image: slim, wearing tight shirts, messenger bags and fashionable eyewear. The result of this convergence is the spread of the belief that "nerd is the new cool". Take, for another example, the character of Seth Cohen in the teen-drama "The O.C." Seth is quite different from the classic stereotype of the nerd: he's not ugly, he's extremely ironic and brilliant, representing the archetypal de-stigmatized nerd, no longer ignored by girls, but often, even desired by them. The emergence of a "nerd elegance" could be seen as the culmination (as well as the beginning of disintegration) of nerd culture as collective identity (Tocci, 2009: 4). The nerd is no longer seen as a subject with poor social skills, but simply as a person with specialized and passionate knowledge.

\section{NERDS AS AN UNIVERSAL CULTURAL FIELD}

While admitting the existence of some fluid and ephemeral social formations, typical of post-modernity, we cannot exclude that formations with relatively high levels of cultural density continue to exist. Along the twentieth century, significant sub-cultural reality emerged: social segments that are detached from the broader culture being - at the same time - part of it, sharing value systems and identity dynamics based on the adoption of discordant lifestyles. The concept of sub-culture still manages to be sociologically effective, at least for those groups that show relatively high levels of "distinction", "commitment" and "autonomy".

Nerd culture may be defined, in this sense, a subculture; without embracing the entire theoretical construct that the school of Birmingham defined in the late 1960s. Even better, we could refer to Pierre Bourdieu "Theory of practice" trying to fight different reductionist theoretical traditions and overcome conceptual dichotomies that have plagued and still torment social thought. In this way we can better interpret the phenomena conventionally called subcultures as sets of integrative practices articulated within specific cultural domains of social life: particularly lifestyle and cultural consumption (Buckingham, 2009). Consumption meant as a daily practice through which culture is interpreted and produced is the subject of research of many disciplines and critical perspectives (Veblen 1899, Baudrillard 1968, Bourdieu 1979, De Certau 1980).

In the frame of a society where class divisions are characterized by fluid permeability, social groups pursue innovative distinctive strategies. In a capitalist system, like the one in which we are "immersed", the personality of an individual, what we can recognize as his ego, can be determined by how he differs from the others, socially and psychologically, through consumption practices. 
Consumption can be seen as a practice of use of meanings, signs and symbols related to the sense of identity articulation of the class; social subjects are classified by their own classifications, by their clothing, and are distinguished from their own distinctions. (Bourdieu, 1979)

Bourdieu sees identity as an image built into a struggle of representations, continuous redefinitions where we all act, classify and are classified. Consumption and lifestyles are linked to the taste, Taste is not the sum of individual preferences: first of all, it "couples and better matches colours, but also people" (Bourdieu, 1979). The taste, socially induced, directs who occupies a particular place in the social space to the practices (or to the assets) that are more appropriate. Full participation in practice presupposes the internalization of guidelines shared: taste infrastructure that limit the right aesthetics in a particular way. Being a nerd, so, is something you do, as implied by the definition of cultural practice. Nerds are not simple "amateurs" but people aware of participating in a shared, global, cultural milieu. If the mass culture, as defined by Morin (1962), is "the first universal culture of history", the nerds are the realization of a universal cultural field.

\section{COMPRISE AND SEPARATE}

Western society is often defined as "society of the image" not only because the images have expanded their dominion overlapping reality itself, but also because the very idea that we have of the society and its structures has more and more to do with the constructions of the imaginary. In this perspective, the choice of clothing takes on new meaning: it becomes a way to reflect on ourselves, on which part of the self to highlight and translate into an image. The traditional bastions of identity, the structural variables that have always characterized the middle class no longer represent a stable reference system able to regulate costumes and behaviours.

Fashion provides the symbols of belonging to a social circle and not to another: it has the double function to comprise us in a circle and, at the same time, separate from the others (Simmel, 1905). The individual, thanks to these practices related to the appearance, composes and decomposes his social representation: the construction of identity, like fashion, becomes a process in continuous renewal. Fashion has an important social function: introduces a pattern of common behaviour among people belonging to a same group, facilitating the construction of a collective identity, through the use of objects and clothes in which members of the group see their values reflected. Wearing or rejecting a particular garment becomes a reaction to the inclusive - or exclusive - will of a social group and its intrinsic rules. Adopting a kind of dress over another becomes a symbolic expression of a significant difference, favouring the construction of a collective identity. Printed T-shirt represents the characteristic garment used by Nerds. This seemingly casual dress rose to the role of "uniform" in a manner similar to what happened in other subcultures, such as Heavy Metal or Goth. I identified, in the first chapter, lack of style as one of the classical stereotypes about Nerds; instead, a real nerd-specific style, with a specific clothes industry does exist. But rather than the style of the garment, more than its aesthetic dimension, I want to focus on the semiotic and intertextual content of T-shirts.

We can define intertextuality as "the complex interrelationship between a text and other texts taken as basic to the creation or interpretation of the text"1. Demonstrating proficiency with the canonical sub-cultural texts is one of the ways in which participants show the ownership of cultural capital. We can consider intertextuality, in this case, not just as a characteristic feature of the texts, but as a real form of creativity. People, in fact, aren't merely publics of the texts, they are active subjects that replicate, transform and change elements of the media they consume. They cite dialogues, emulate styles, hum songs they learn from television, radio and cinema. The knowledge of the texts, the ability to show this skill, is a form of cultural capital highly rated in some areas of society. Nerd culture is certainly part of these areas, in particular through the use of quotations or wearing a particular kind of clothing, halfway between style and citation. Knowledge of citations is also a way of keeping high boundaries to certain groups. The ability to participate actively to intertextuality distinguishes who owns a particular cultural capital from who doesn't. By coding in their clothing references to the imaginary, nerds are able to use these T-shirts as a sign of belonging, exclusively decipherable by their peers that share the same cultural capital.

Frequently these T-shirts depict subjects that may appear childish, with simple references to elements of the mass culture; at the same time they are very complex to decode for those without a thorough knowledge of the subject. As in the case of mashups, compositions achieved by combining together two or more citations. I refer them as "intertextual puzzle": a mix of popular culture subjects, belonging to different universes such

\footnotetext{
${ }^{1}$ Definition taken from Merriam, Webster (2005) The Merriam-Webster Dictionary
} 
as cinema, television and video games; an amalgam of multiple quotes, only understandable by those who deeply know the rules of the sub-cultural field.

\section{NERD-WEAR}

The proliferation of e-commerce platforms and the streamlining of industrial production has allowed, through the phenomenon known as "the long tail" (Anderson, 2006), the emergence of many market segments aimed by the industry with specific products.

Our culture and our economy are freeing from the importance given to a small number of products, markets, services - the so called mainstream - that are placed on the head of the demand curve, and are moving towards a large number of niches. In an age no longer subject to the constriction of the exhibition spaces, in both physical and temporal way, the industry offers a huge amount of goods and services to these small target niches that potentially represent a more attractive market than the one obtained with a few mass products. Nerd clothing is one of those niches that are becoming increasingly important.

Let's analyse in detail some examples of these shirts, looking at the products of some leading companies like "Threadless" or "Naolito tees". Threadless is an online community of artists and an e-commerce, founded in 2000, by Jake Nickell and Jacob DeHart. Their designs are created and chosen by an online community. Based on the community feedback, about 10 designs are selected each week, printed on clothing and other products, and sold worldwide. This kind of structure, based on crowd sourcing, is perfectly suited to the creation of the specific garment made, in our case, from nerds to nerds.

\subsection{Banana Fiction}

This T-shirt (Fig. 1),designed by the artist Alberto Arni and sold on Threadless, is a perfect example of mashup of quotes involving different forms of cultural capital that require, to be interpreted and understood completely, an in-depth knowledge of different contexts: in this case movies, animation and pop-art.

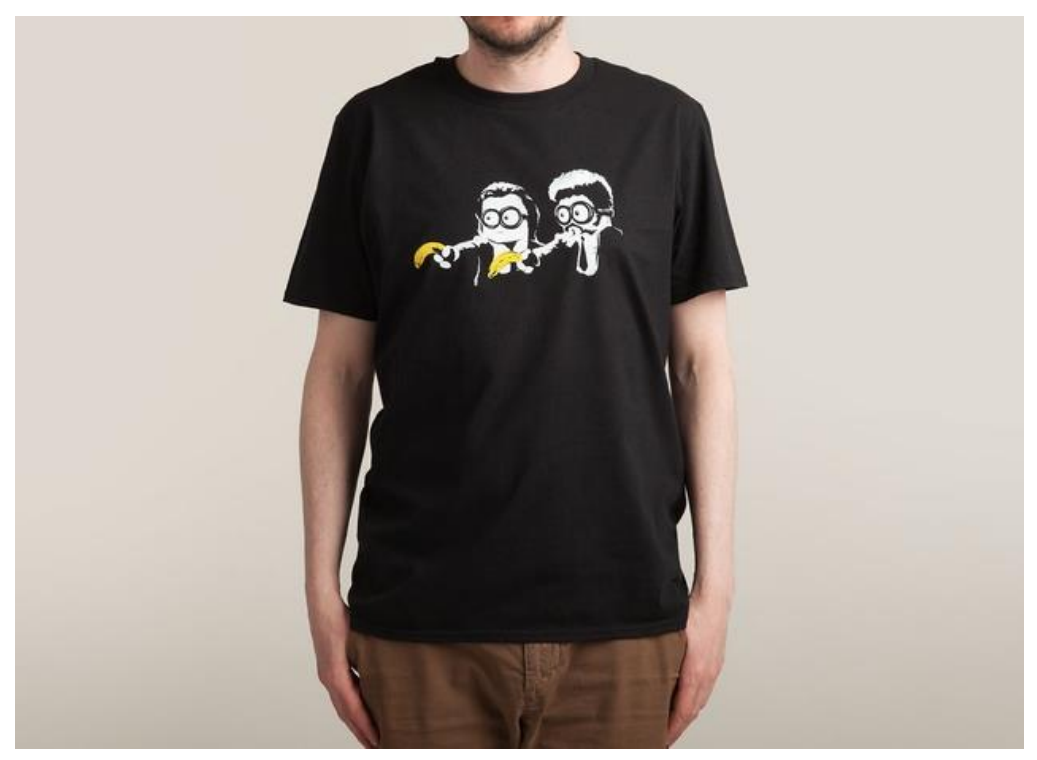

Fig. 1: Banana Fiction T-shirt from www.threadless.com

Printed on the illustrated shirt we see two Minions, Jerry and Dave, two characters from the animated film "Despicable me" who, wearing a suit, wield two bananas as if they were guns.

The "minions" are the handyman henchmen of Gru, the film's protagonist. Their main task is to follow and help their "boss" in his "evil" missions.

Trying to decipher the pattern of citations included in this illustration, we can find the first reference to the work of the street artist called "Banksy", painted on the walls of the "Old Street" (Fig. 2) underground station in London until April 2007 (before being deleted from diligent - as insensitive to art - employees of the London Underground). 


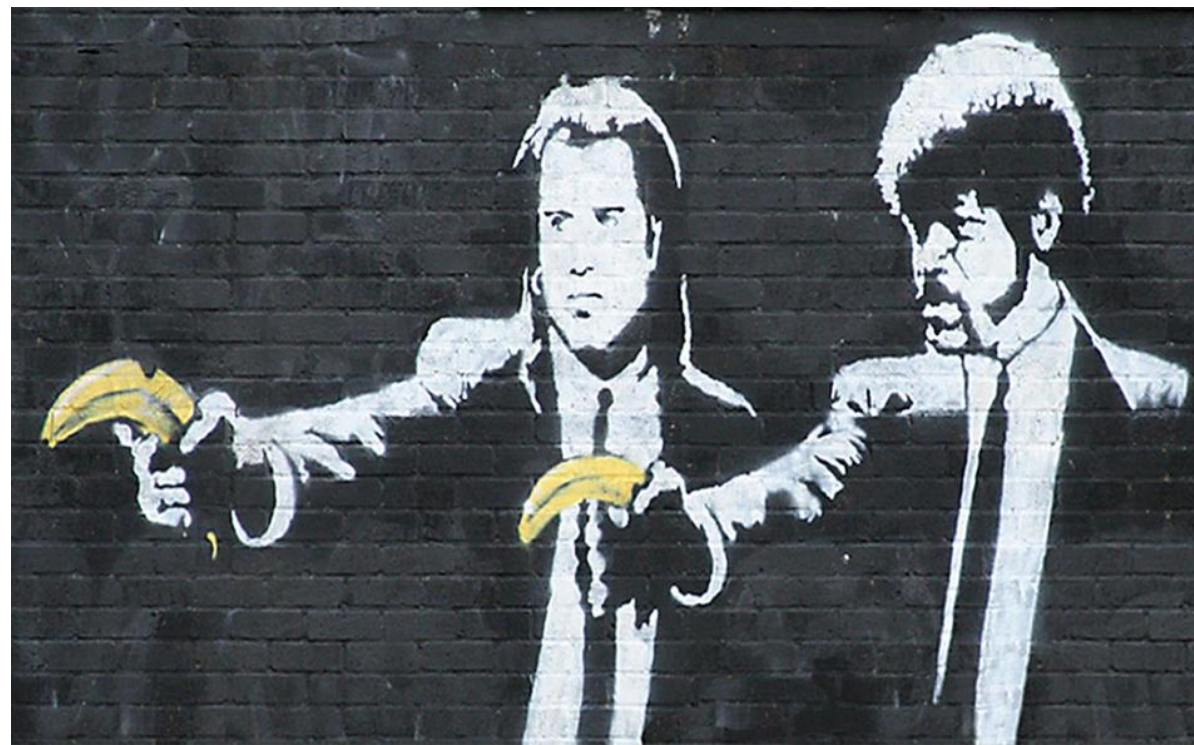

Fig. 2: Banksy mural in old street, London

The Old Street wall painting is considered one of his most representative works, as well as one of the oldest, since it has been for more than 5 years in the central location of the capital, portraying John Travolta and Samuel L. Jackson in the shooting position holding two bananas instead of guns. A perfect example of "Pulp Art", the transposition of Tarantino's philosophy in painting, mixed with the irreverent spirit of Banksy.

The street art opera recalls an iconic scene of one of the most successful Quentin Tarantino's movies, "Pulp fiction". We can see (Fig. 3) the frame that inspired Banksy and, subsequently, Alberto Arni.

In this movie the two actors play the role of two henchmen - or, at this point, we could say two minions - in the service of the mob boss Marsellus Wallace.

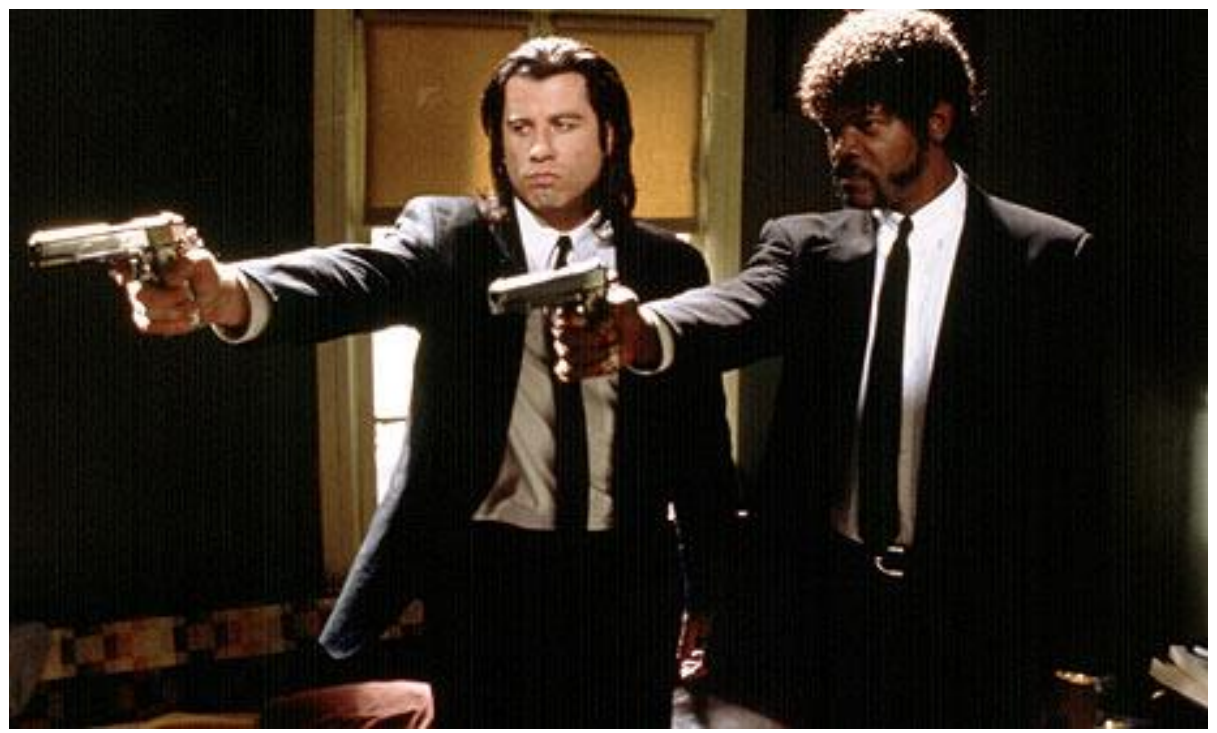

Fig. 3: John Travolta and Samuel L. Jackson in Quentin Tarantino's "Pulp Fiction"

What it may appear as a simple T-shirt with a childish drawing, showing two characters of an animated movie, it is actually a complex mashup of quotes, an intertextual puzzle that can be recognized, as I stated earlier, and decoded only by those who have a suitable cultural capital.

With a certain amount of irony, Jerry and Dave, "minions" from the movie "Despicable Me", are likened to Travolta and Jackson. Instead of guns they wield two bananas (fruit that characterizes them, being their only food) as in the Banksy mural art. 


\subsection{Dawn of Gaming}

This T-shirt (Fig. 4), on sale on www.naolito.com, shows an illustration difficult to understand at first glance. We see, in a desolate valley, a huge joypad standing. We can recognize the iconic peripheral of the Nintendo Entertainment System (NES) console. Some gorillas watch it from a distance, seeming scared. One of them, wearing an extravagant red tie and surrounded by barrels, approaches and touches it.
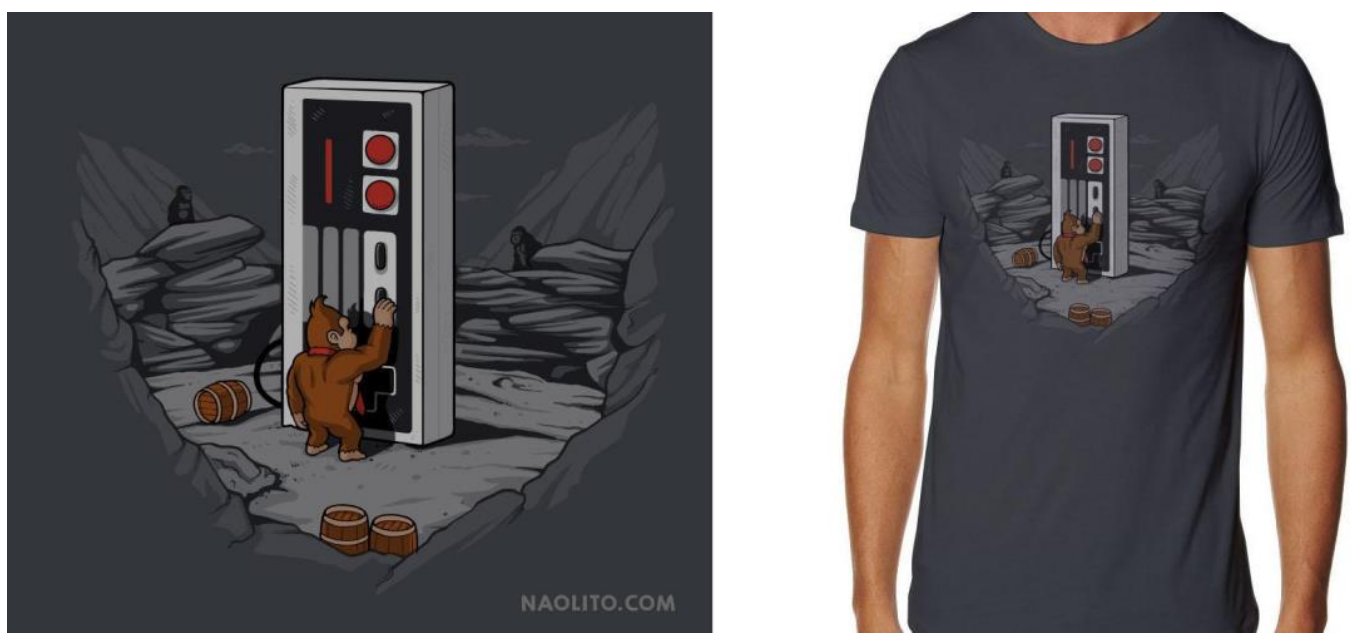

Fig. 4: Dawn of gaming T-shirt, from www.naolito.com

Knowing the world of video games, it is not difficult to recognize the gorilla in the foreground: it is Donkey Kong (ドンキーコング Donkī Kongu), a character created by Shigeru Miyamoto as the antagonist of Mario (the iconic character from Nintendo) in the video game "Donkey Kong" (Fig. 5) and starring, later, in many other Nintendo games.

Donkey Kong appears for the first time in the homonymous video game. The Gorilla kidnaps a blonde girl bringing her on the top of an under construction building.

Mario, the hero, will try to save her from its clutches, climbing the building and avoiding barrels thrown by the gorilla. The idea of the gorilla in love that kidnaps the girl reminds us, of course, the extraordinary film King Kong (1933). In 1994, with the launch of the Game Boy version of the video game, the character is redrawn wearing, since then, an iconic red tie (Fig. 5).
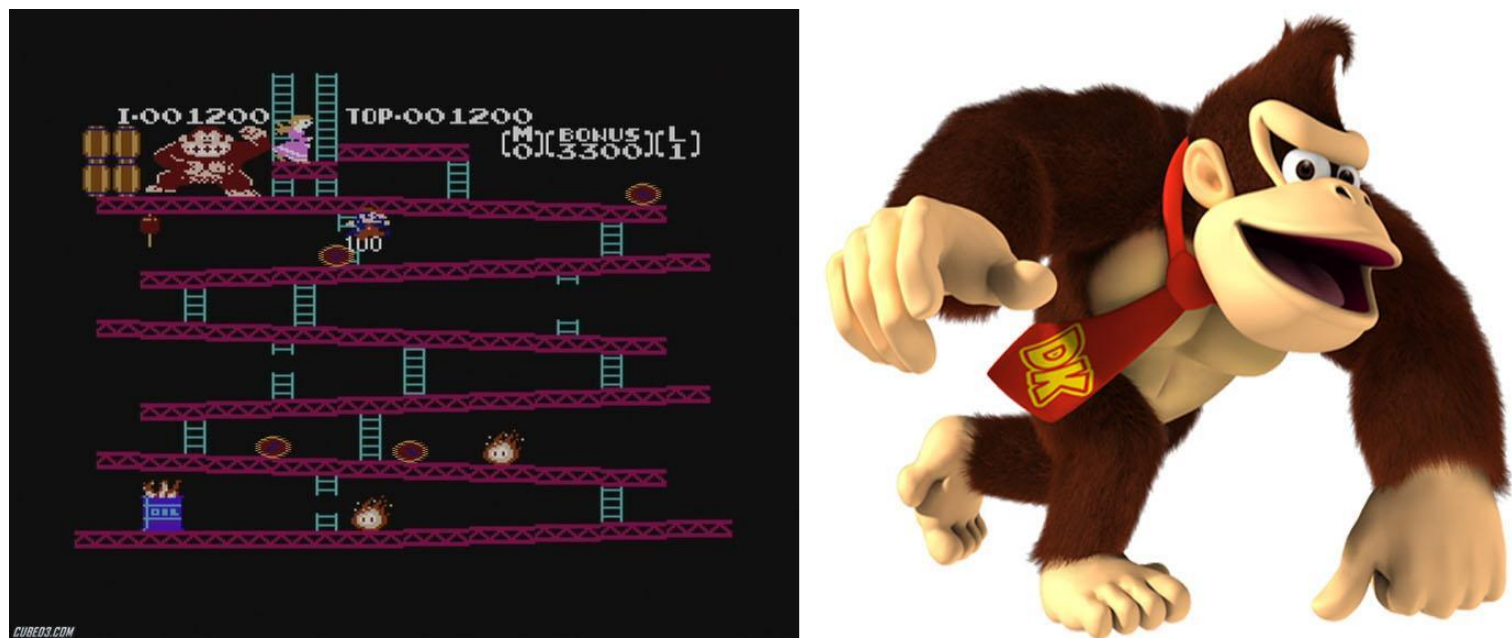

Fig. 5: Donkey Kong videogame screenshot, Donkey Kong 1994 restyling

Let's try to decipher the rest of the scene. Monkeys intrigued by a huge monolith in a desolate valley. Anyone who loves cinema will recognize one of the most famous scenes in movie history: the so called "the dawn of man" from Stanley Kubrick's "2001: a space odyssey"(Fig. 6).

A group of hominids, led by their head, barely survives in a barren and hostile environment. One day in front of their cave a large black monolith mysteriously appears. Hominids, coming into contact with it learn how to use tools to hunt animals and to defend the territory by killing enemies. 


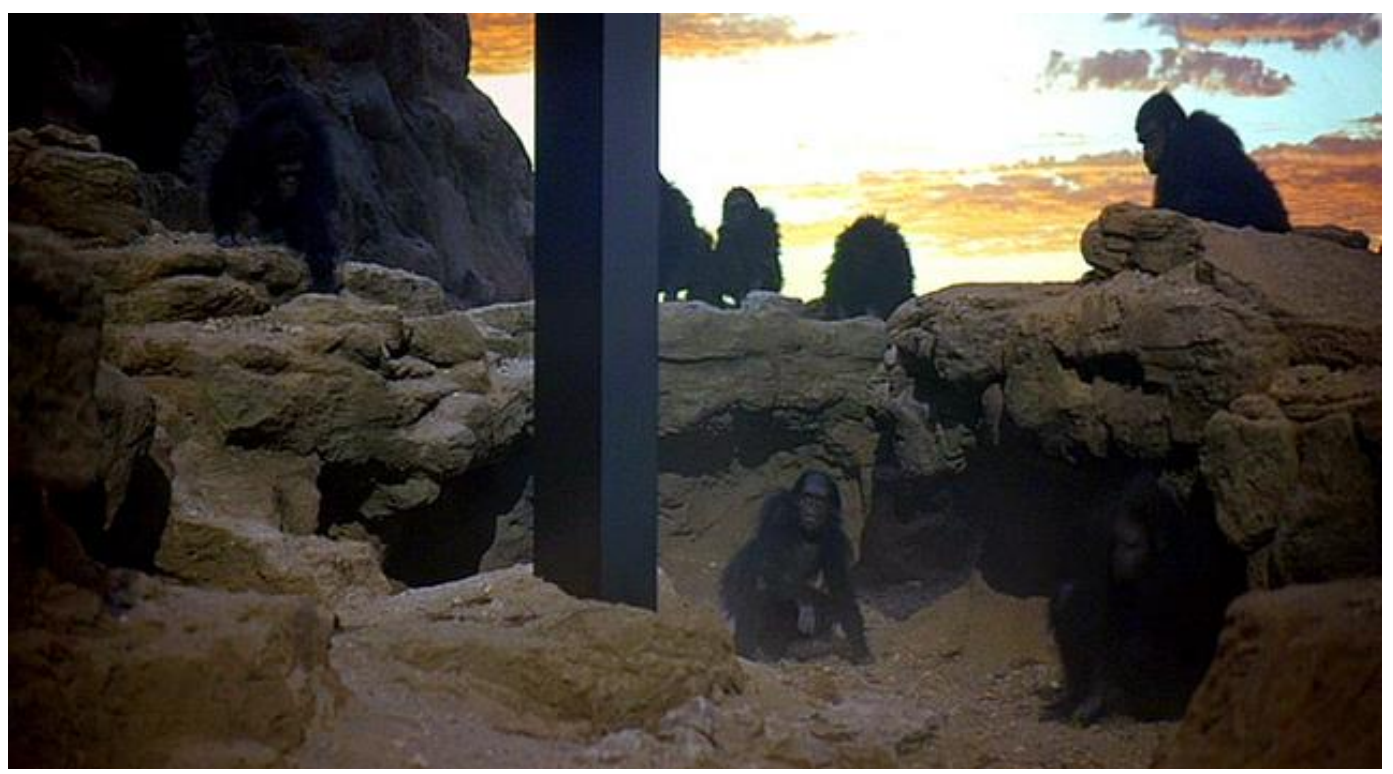

Fig. 6: Stanley Kubrick's "The dawn of man" from "2001: a space odyssey"

The idea of the artist who designed this T-shirt is that the Nintendo joypad represents, in a broad sense, the dawn of video-gaming. Although not the first video game console ever, Nintendo Entertainment System was certainly the most significant, the one that historically has approached to this world millions of fans. The joypad, as the Kubrick's monolith, is the tool to take full control of the universe, giving the gamer ultimate power. Therefore, this shirt is another example of "exclusive" garment that allows, in a non-verbal way, to communicate membership in a particular social group and knowledge of its culture, allowing instantaneous mutual recognition by those who possess the keys to decode it.

\section{CONCLUSION}

Revenge of the Nerd is in a status of perpetual reaching for a completion which is never accomplished. Despite an apparent de-stigmatization of nerd culture is taking place, many of the negative stereotypes persist. More and more people accept the comics, video games, science fiction, role-playing games as legitimate forms of cultural expression and not just as trivial leisure interests. However, you can still be considered a "loser": the stereotype of the sloppy nerd, alone in his room escaping every social relationship not mediated by a screen, facing the sunlight only when absolutely necessary, still exists. Of course, there is not an actual person fitting into this stereotype, yet it is still exists in the media as in everyday speech, as a kind of warning to "don't be too nerd." The meaning of being Nerd is always the result of a negotiation defined in a social context (Boyd, 2008). To be a "good nerd" or a "bad nerd" depends on who is talking and what about. In common sense, "to be nerd" is considered a synonymous with "being passionate about something" a rhetoric that legitimates consumer practices regardless of their status in the hierarchy of traditional culture.

What may seem futile, as the most common genres of pop culture, when it becomes a cultural practice can grow as a driving force in the development of individual and collective identities? Understanding the nature of these communities and practices of signification that take place within them helps us understand the possibilities - and limitations - of recreating communities in our daily experience. We live in a society where people begin to understand the need to accept the fact that their views are often an expression of a minority without trying to impose a "normal" vision. A culturally healthier society, where the "revenge of the nerds" is finally fulfilled in a world in which everyone is, in some way, nerd for something.

\section{REFERENCE LIST}

Anderson, C. (2006). The Long Tail: Why the Future of Business is Selling Less of More. New York: Hyperion

Baudrillard, J. (1968). Le Système des Objets. Paris: Gallimard.

Bourdieu, P. (1979). La Distinction. Critique Sociale du Jugement. Paris: Editions de Minuit.

Boyd, D. (2008). Taken Out of Context: American Teen Sociality in Networked Publics. PhD Dissertation. University of California-Berkeley, School of Information. 
Brancato, S. (2010). La Forma Fluida del Mondo - Sociologia Delle Narrazioni Audiovisive Tra Film e Telefilm. Ipermedium Libri.

Buckingham, D. (2008). Youth, Identity, and Digital Media. Cambridge, MA: MIT Press.

Certeau, M. (1980). Arts de faire. (L'Invention du quotidien). Paris: Union Générale d'éditions.

Kendall L., (2011). "'White and Nerdy": Computers, Race, and the Nerd Stereotype”. The Journal of Popular Culture. 44 (3).

Morin, E. (1962). L'esprit du Temps. Paris; Éditions Grasset

Nugent, B. (2008). American Nerd: The Story of My People. New York: Simon and Schuster.

Simmel, G. (1905). Philosophie der Mode. Berlin: Pan-Verlag.

Tocci, J. (2009). Geek Cultures: Media and Identity in the Digital Age. Publicly Accessible Penn Dissertations. Paper, 953

Tonnies, F. (1887). Gemeinschaft und Gesellschaft. Abhandlung des Communismus und des Socialismus als empirischer Culturformen. , Darmstadt: Wissenschaftliche Buchgesellschaft.

Veblen, T. (1899). The Theory of the Leisure Class. New York: The New American Library. 